\title{
A GERAÇÃO DIGITAL PRODUZIDA NOS ANÚNCIOS PUBLICITÁRIOS: VENDENDO UMA INFÂNCIA TECNOLÓGICA NA REVISTA VEJA
}


A GERAÇÃO DIGITAL PRODUZIDA NOS ANÚNCIOS PUBLICITÁRIOS: VENDENDO UMA INFÂNCIA TECNOLÓGICA NA REVISTA VEJA

Resumo: Articulado a partir dos Estudos Culturais, este trabalho dedica-se a investigar como a Geração Digital vem sendo representada nos anúncios publicitários da Veja. Utilizam-se como aporte teórico os conceitos de Pedagogia Cultural, Consumo e Representação. Essa análise discute também como a relação entre infância e tecnologia tem sido naturalizada e vendida.

Palavras chave: pedagogia cultura; consumo; publicidade; representação; Geração Digital

\section{LA GENERACIÓN DIGITAL PRODUCIDA EN COMERCIALES: VENDENDO UNA INFANCIA TECNOLÓGICA EN LA REVISTA VEJA}

Resumen: Vinculado a los Estudios Culturales, este trabajo se dedica a investigar cómo la Generación Digital está siendo representada en los anuncios de Veja. Se utiliza de los conceptos teóricos de Pedagogía Cultural, Consumo y Representación. Este análisis también aborda cómo la relación entre los niños y la tecnología se ha naturalizado y es vendida.

Palabras clave: pedagogía cultural; Consumo; publicidad; representación; Generación Digital

THE DIGITAL GENERATION PRODUCED IN ADVERTISING: SELLING A TECHNOLOGICAL CHILDHOOD IN VEJA'S MAGAZINE

Abstract: Articulated from Cultural Studies, this study is dedicated to investigate how the Digital Generation is being represented in the advertisements of Veja's magazine. The concepts of Cultural Pedagogy, Consumption and Representation are used as theoretical approach. This analysis also discusses how the relationship between childhood and technology has been naturalized and sold. Keywords: cultural pedagogy; consumption; publicity; representation; Digital Generation 


\section{INTRODUÇÃO}

Numa sociedade de consumidores, todo mundo precisa ser, deve ser e tem que ser um consumidor por vocação (ou seja, ver e tratar o consumo como vocação). Nessa sociedade, o consumo visto e tratado como vocação é ao mesmo tempo um direito e um dever humano universal que não conhece exceção. (BAUMAN, 2008, p.73)

De fato, na sociedade em que vivemos, o mercado consumidor não respeita exceções. Ao contrário, o consumo está em todos os lugares e alcança as mais variadas culturas. Um dos aspectos mais complexos, bem elaborados e que vem sendo discutido por diferentes segmentos da sociedade é o que trata da relação entre infância, tecnologias e consumo.

Folheando os anúncios publicitários de diversas revistas, nos foi permitido visualizar a importância da publicidade na formação de uma infância tecnológica. Crianças manuseando e operando artefatos tecnológicos - como celulares e tablets - em anúncios publicitários vêm sendo utilizadas para evidenciar um natural vínculo com as tecnologias. É fato que hoje ninguém consegue melhor explorar com tanta versatilidade as máquinas quanto os jovens. Esse tipo de habilidade chama a atenção de educadores, comunicadores, filósofos e sociólogos porque o ritmo e o consumo ditados pelas tecnologias parecem decisivos para formar os sujeitos desta geração que adentram o século XXI.

Nesta perspectiva, o objetivo da presente pesquisa é investigar como a Geração Digital - denominação conferida às crianças nascidas desde meados da década de 1990 e que possuem habilidades com os aparatos tecnológicos vem sendo representada nos anúncios publicitários da revista Veja.

Entendendo os Estudos Culturais como um produtivo campo para analisar a história do presente, este trabalho reúne achados de uma pesquisa de Mestrado concluída e de outra de Doutorado em andamento ${ }^{1}$ que tratam sobre infância e tecnologia. A partir da articulação entre a área da comunicação e da educação, este estudo dedica-se à análise de peças publicitárias veiculadas na Revista Veja do período de 2001 a 2011, compreendendo um conjunto de

1 Trata-se da pesquisa de Mestrado desenvolvida por Paula Deporte de Andrade denominada "A formação da infância do consumo: um estudo sobre crianças nos anúncios publicitários da Revista Veja” na ULBRA e da pesquisa de doutorado que está sendo desenvolvida por Sandro Facchin Bortolazzo denominada "Representações da Geração Digital” na UFRGS. 
60 exemplares. Como critério, selecionamos seis grupos de edições que correspondem às 10 primeiras de cada série, num total de 100. Assim, analisamos os exemplares correspondentes às edições de números 1701-1710; 1801-1810; 1901-1910; 2001-2010; 2101-2110; 2201-2010 e procuramos observar todas as peças publicitárias que faziam referência ou traziam crianças como protagonistas e consumidoras de tecnologia.

Desse modo, nas próximas seções, problematiza-se, inicialmente, o que implica ser um sujeito integrante da Geração Digital. Logo após, desenvolve-se uma discussão sobre como a publicidade, ao associar crianças e tecnologia, vem operando como uma Pedagogia Cultural. Por fim, procedemos às análises das peças publicitárias. Diante delas foi possível verificar que os anúncios publicitários colocam em prática saberes que ao representar também produzem uma geração digital.

\section{PARA PENSAR UMA GERAÇÃO DIGITAL}

Inúmeros debates têm sido suscitados acerca do termo "geração" ou "gerações". Portanto, o que fizemos aqui é situar brevemente de que referencial teórico abordamos a questão geracional e também sob quais circunstâncias hoje é possível falar de uma Geração Digital.

Seguindo a linha histórica apontada nos estudos desenvolvidos por Feixa e Leccardi (2010), há três acepções para o conceito de geração: uma ligada à sociologia de Comte e Dithey, outra conectada aos estudos de Mannhein e uma terceira baseada nos estudos de Abrams. Esta terceira e última análise do conceito de geração, inspirada em Abrams, aborda a questão das gerações entre o tempo histórico e a identidade. Pensamos ser essa a abordagem da qual mais nos aproximamos, já que esse autor amplia a noção histórica e social e relaciona o termo geração à questão da identidade. Consideram-se então as duas esferas, a do tempo histórico e a do tempo social onde reciprocamente emergem as gerações. De acordo com os sociólogos Feixa e Leccardi (2010), para Abrams geração é o período de tempo no qual a identidade é construída a partir de significados que estão socialmente e historicamente disponíveis. Assim, é possível falar que as gerações "não surgem da cadência temporal estabelecida por uma sucessão de gerações biológicas. Em outras palavras: não há padronização do tempo para medir ou prognosticar seu ritmo" (FEIXA; LECCARDI, 2010, p. 191). Dessa forma, uma geração pode sim ser compreendida 
num período de dez anos, por exemplo, mas também cessa quando novos e grandes eventos históricos, ou melhor, quando processos econômicos e de natureza cultural tornam o sistema anterior e todas as experiências relacionadas a ele sem significado.

Considerando, então, o termo geração como fruto dos processos sociais e históricos produzidos a partir de experiências compartilhadas, por meio de uma exposição sucinta da imersão das tecnologias na vida em sociedade, iniciamos pelo o que parece ser o aspecto mais significativo na compreensão da formação de uma Geração Digital, a evolução dos meios de comunicação.

Durante a Idade Média, quando um evento de importância local ocorria, os adultos costumavam repetir seus aspectos várias vezes para as crianças a fim de que o acontecimento fosse lembrado por toda a vida delas. Como os aldeões medievais, cada um de nós carrega um repertório de fatos, memórias e lembranças que, de alguma maneira, estão gravadas em nossa consciência. No decorrer da história, o homem criou a necessidade de registrar os fatos a sua volta e desenvolveu métodos, mecanismos e criou suportes para armazená-los. Tudo isso teve o intuito de preservar a memória dos eventos mais importantes e fazê-los sobreviver ao tempo. Uma necessidade de preservação da história foi crescendo na medida em que os meios de operação tornaramse mais rápidos tanto no que se refere à armazenagem de informações, bem como de sua disposição e disseminação.

Até a década de 1950, por exemplo, as pessoas em geral dispunham de fôlego para se adaptar às novidades no campo das tecnologias e da transmissão de dados. Na primeira década do século XX, deu-se a expansão do rádio e a base de informação para a maior parte da população se dava através dos jornais impressos e dos livros. Demorou muito tempo até surgir a televisão em preto e branco (no Brasil na década de 1950), restrita ainda a um ou dois canais disponíveis. Mais alguns anos, chegamos a televisão em cores com o ingresso de outras emissoras. De fato, a partir da televisão em cores, menos tempo ainda se levou até surgir a televisão por assinatura, via satélite, os computadores e a internet.

Net Generation, Geração Digital, Nativos Digitais, Cyberkids, Geração Z, Geração Online, Geração Google, Geração Multimídia, Geração Conectada, Geração Internet, Geração Facebook. Essas entre outras nomenclaturas têm sido utilizadas por autores e também pelos meios de comunicação para nomear as crianças e os adolescentes nascidos junto com tecnologias digitais.

É unanimidade nas obras citadas que o mundo desses jovens desde sempre 
foi povoado por computadores, internet, $\mathrm{MP} 3$, e-mail e, de certa forma, conhecem e vivenciam um mundo que os atrai sempre com novidades a todo o momento. Nesse sentido, o que se observa é que estamos diante de uma Geração que se destaca por uma intensa relação com os aparatos tecnológicos, o que resultou no domínio dos mesmos.

O livro Grown up digital: how the net generation is changing your world (2009), do professor da Universidade de Toronto Dan Tapscott é uma das obras que analisa as relações encaradas pelos jovens e as novas tecnologias. Tapscott apresenta um estudo sobre as representações da chamada Geração Digital, correspondendo às crianças e adolescentes nascidos desde meados da década de 1990 - período no qual a efervescência de parafernálias digitais passou a fazer parte do cotidiano dos jovens norte-americanos (reduto da pesquisa do autor).

Oito características, ou normas, descrevem um típico sujeito da Geração Digital e os diferenciam dos seus pais, os boomers. Eles prezam a liberdade e a liberdade de escolha. Eles querem personalizar as coisas, tornando-as próprias. Eles são colaboradores naturais, que gostam de uma conversa, não de palestras. Eles irão analisar minuciosamente você e a sua empresa. Insistem na integridade. Eles querem se divertir, mesmo no trabalho ou na escola. Velocidade é algo normal. A inovação é parte da vida. (TAPSCOT, 2009, p. 6 - Tradução nossa²).

É uma geração que prescinde de informações e estímulos e o próprio ritmo ditado pela tecnologia é decisivo para formar os sujeitos desta Geração que não compreendem a si mesmo sem uma certa digitalização do mundo. Para usar uma expressão de Marky Prensky (2001), esses sujeitos podem ser considerados especialistas digitais, possuidores de uma capacidade múltipla, ou seja, aptos a utilizar diversas mídias ao mesmo tempo. É por isso que o autor vai classificá-los como "Nativos Digitais", em oposição aos seus pais ou professores que nasceram antes e que, portanto, seriam os "Imigrantes Digitais".

Então, como se pode perceber, a produção desta Geração Digital é uma construção histórica possível a partir da imersão das tecnologias na vida em

2 No original: Eight characteristics, or norms, describe the typical Net Gener and differentiate them from their boomer parents. They prize freedom and freedom of choice. They want to customize things, make them their own. They're natural collaborators, who enjoy a conversation, not a lecture. They'll scrutinize you and your organization. They insist on integrity. They want to have fun, even at work and at school. Speed is normal. Innovation is part of life. (TAPSCOT, 2009, p. 6) 
sociedade. Neste sentido, a publicidade, como qualquer outro artefato cultural, ao representar esta geração em seus anúncios não está "inventando" estes sujeitos, mas colocando em circulação uma representação que já se encontra difundida no campo social. Contudo, ao dar espaço para tal representação, as peças reforçam certas características e contribuem para produzir um conjunto de saberes acerca desses sujeitos. Análises deste tipo só são passíveis de serem desenvolvidas porque as lentes teóricas dos Estudos Culturais nos permitem proceder com tais articulações.

\section{USANDO OS ESTUDOS CULTURAIS PARA PROBLEMATIZAR ANÚN- CIOS PUBLICITÁRIOS DE REVISTAS}

Na perspectiva teórica em que nos inscrevemos, compreendemos os Estudos Culturais como um profícuo campo para se romper com algumas formas tradicionais de pensar. Trata-se de um campo que busca não a verdade do que está posto, mas a compreensão de como as coisas chegam a ser o que são, como são construídas e igualmente como são representadas. Com isso, consideramos que, ao articular este campo de saber com outros, como o da comunicação, temos condições de olhar com novas lentes questões que estão na nossa sociedade, na nossa cultura. Além disso, concordamos com Grossberg (2008) quando afirma que devemos evitar reproduzir os universalismos e essencialismos que muitas vezes predominam nas produções de conhecimento.

De acordo com o autor:

Consequentemente, qualquer formação de estudos culturais tem de continuamente refletir sobre o seu próprio contexto, sobre as questões que coloca a si própria, e sobre as ferramentas que utiliza para responder a esse desafio. (GROSSBERG, 2008, p. 18).

Inspirados nessa assertiva e com o objetivo de articular dois distintos campos de saber, elencamos como ferramentas teóricas os conceitos de Pedagogia Cultural, Consumo e Representação com o intuito de responder ao desafio que nos propomos: mostrar como a publicidade vem colaborando para a naturalização da relação entre crianças e artefatos tecnológicos.

Por Pedagogia Cultural entende-se "qualquer instituição ou dispositivo cultural que, tal como a escola, esteja envolvido - em conexão com relações de poder - no processo de transmissão de atitudes e valores" (SILVA, 2000, p.89). 
Steinberg e Kincheloe (2004, p.14) afirmam que a Pedagogia Cultural:

[...] enquadra a educação numa variedade de áreas sociais, incluindo mas não se limitando à escolar. Áreas pedagógicas são aqueles lugares onde o poder é organizado e difundido, incluindo-se bibliotecas, $\mathrm{TV}$, cinemas, jornais, revistas, brinquedos, propagandas, videogames, livros, esportes, etc.

E a publicidade é um dos artefatos culturais que tem sido muito produtivo como pedagogia cultural. Em especial a publicidade que usa crianças tem sido eficaz ao ensiná-las a serem consumidoras; ao ensinar e orientar seus gostos na hora da compra; ao ensinar que a relação entre infância e tecnologia é algo dado como natural. Enfim ao ensinar uma multiplicidade de conhecimentos que atuam produtivamente na constituição destes jovens sujeitos.

Segundo Amaral (2000,p.152):

Assim como as demais imagens veiculadas pela mídia, as imagens publicitárias são saturadas de posições e oposições que impõem ressignificações. A publicidade ensina uma visão de mundo, valores e aqueles comportamentos que são ou não, socialmente aceitáveis.

Evidentemente, numa sociedade capitalista, onde o consumo é uma das dominantes culturais, muito do que a publicidade nos ensina está relacionado ao poder de compra dos sujeitos. Assim, é por intermédio da publicidade, mas também por intermédio de vários outros artefatos de nossa cultura, que as crianças aprendem a serem sujeitos de um certo tipo, no caso aqui, consumidores de tecnologia.

Nesse sentido, a publicidade atua como Pedagogia Cultural não apenas porque está anunciando, vendendo um produto, mas também porque está vendendo uma representação de como ser criança na contemporaneidade. Esse duplo jogo é uma das principais características que faz com que pensadores como Bauman (2008) afirme que hoje vivemos numa "sociedade de consumidores". De acordo com o autor nesta sociedade não há a divisão entre coisas a serem escolhidas e os que as escolhem, entre mercadorias e consumidores. Bauman (2008,p.20) complementa sublinhando que, na sociedade de consumidores, "o que a separa de outras espécies de sociedade é exatamente o embaçamento e, em última instância, a eliminação das divisões acima citadas".

Essa eliminação das divisões permite que representações que circulam no 
campo social sejam naturalizadas pelos artefatos midiáticos como a publicidade. Nessa assertiva, alicerçados no referencial teórico dos Estudos Culturais, é importante que compreendamos que quando falamos em representação não estamos falando de representação como espelho da realidade, mas como uma construção cultural. É por isso que, para Hall (1997), há um sistema no qual fomos ensinados fazer referência ao mundo, às pessoas e aos eventos a nossa volta e, assim, estaríamos inscrito em um processo de tradução - a construção de signos. Os signos ou sinais são organizados em linguagem e a existência de uma linguagem em comum permite-nos traduzir nossos conceitos em palavras, sons, imagens e usá-los para expressar significados. Esta tem sido a forma objetiva pelo qual nos tornamos, desde crianças, sujeitos culturais. Não porque este conhecimento estaria impresso em nossa consciência, mas porque permite compartilhar as mesmas capacidades de expressão e comunicação. Nesse sentido, o que se confere é que o significado não é natural às coisas existentes no mundo, mas construído, produzido. É o resultado de uma prática de significações.

Assim, não há de haver qualquer relação simples de reflexão, imitação ou correspondência entre a linguagem e o mundo real. Os processos de significação só ocorrem em função das convenções associadas à linguagem, que funciona, assim, como um sistema de codificação do mundo, reconhecido e aceito por cada cultura. Finalizando, Hall adverte que o significado é produzido pela prática, pelo trabalho da representação.

Nessa perspectiva, este estudo vai ao encontro do que Silva (2001, p.53) afirma fazendo referência ao uso do termo representação nas pesquisas. Segundo esse autor, "nas análises baseadas na noção de representação não se trata de restabelecer a verdade, mas de tornar visíveis as relações de poder envolvidas no processo de representação". São análises baseadas nas relações que tornam visível a naturalização entre infância e tecnologia que o capítulo a seguir discute.

\section{CRIANÇAS VENDENDO TECNOLOGIA: A NATURALIZAÇÃO DA GERA- ÇÃO DIGITAL NA CONTEMPORANEIDADE}

As batalhas travadas em torno da cultura do consumo infantil não são menos do que batalhas sobre a natureza da pessoa e o escopo da individualidade no contexto do alcance sempre crescente do comércio. $O$ envolvimento das crianças com as coisas materiais, a mídia, as 
imagens, e os significados que surgem se referem e se emaranham com o mundo do comércio, são aspectos centrais na construção de pessoas e de posições morais na vida contemporânea. (COOK apud BAUMAN, 2008, p. 73)

Como já apontado, a tecnologia se faz presente de diversos modos na vida dos sujeitos jovens contemporâneos. Hoje, não é mais possível pensar uma sociedade sem a inclusão das mesmas, já que cada interface que surge legitima outros processos sociais. Quando se trata de sujeitos pertencentes à Geração Digital, essa relação é ainda mais forte, pois estes já nasceram inscritos em uma cultura que simplesmente desconhece outro modo de vida que não inclua computadores, celulares e videogames.

As crianças de hoje, percebidas como os sujeitos que garantem a continuidade da atual configuração econômica e social, são alvos das corporações mercantis que aliam infância, tecnologia e consumo. Os anúncios publicitários analisados corroboram tal assertiva, a de que as crianças são utilizadas tanto para vender quanto para consumir tecnologia.

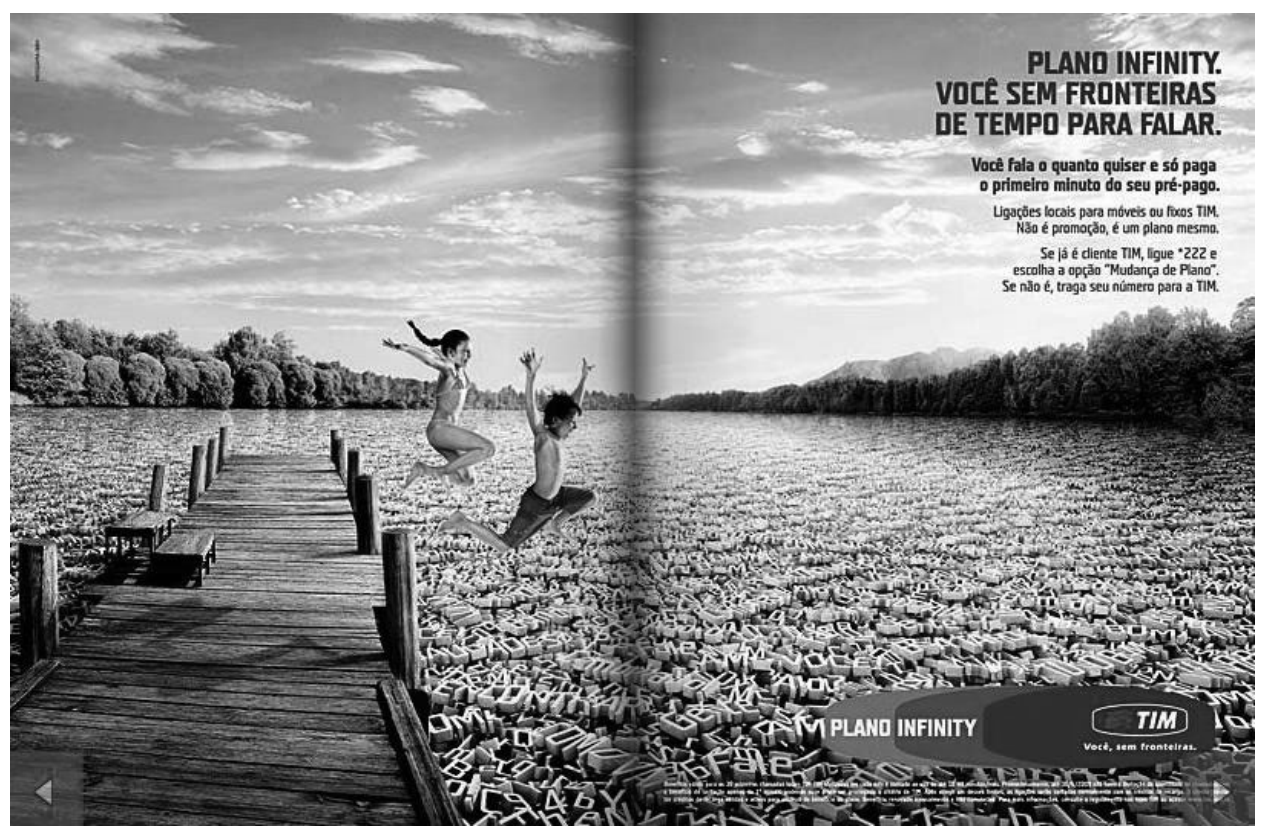

Figura 1 - Revista Veja ${ }^{\circ} 2108$, de 15/04/2009, p. 44-45³

3 Redação do anúncio: Plano infinity. Você sem fronteiras de tempo para falar. Você fala o quanto quiser e só paga o primeiro minuto do seu pré-pago. Ligações para móveis ou fixos TIM. Não é promoção, é um plano mesmo. Se já é cliente TIM ligue *222 e escolha a opção "mudança de plano", se não é, traga seu número para a TIM. 
Iniciamos nossa discussão com o anúncio da empresa de telefonia Tim (fig.1). Como podemos observar no anúncio, embora o mesmo não mostre nenhum aparelho telefônico à venda, já que o que anunciam é um plano de serviços para telefone - o Tim Infinity - pode-se observar algumas estratégias para representar o elo entre crianças e tecnologias. Tendo como protagonistas duas crianças, um menino e uma menina, saltando em um rio, a peça publicitária nos mostra que não se trata de um rio comum, já que ao invés de água, o mesmo é composto por números, letras, códigos. Contudo, mesmo sendo um rio diferente, as crianças não se amedrontam diante dele, pois a imagem delas saltando felizes e livremente anuncia que elas estão integradas aos elementos tanto materiais (telefones) quanto simbólicos (códigos) que representam as tecnologias.

Outro modo para naturalizar tal relação, se apóia em apelos emocionais. Isso significa que, segundo Linn (2006), o apelo não é feito por acaso ou por coincidência, uma vez que os profissionais do campo publicitário sabem que, se conseguirem despertar as emoções de seus consumidores, a chance do objeto anunciado ser consumido é muito maior. Isso porque "a emoção concentra atenção, determina o que lembramos, molda opiniões, motiva e nos conduz à ação. Não deveria nos surpreender, portanto, que os centros emotivos do cérebro tornem-se o alvo primário dos profissionais de marketing e dos publicitários" (WALSH apud LINN, 2006, p. 78). O anúncio abaixo, ao mostrar um bebê para vender a marca da Abril, reforça esse argumento (fig. 02).

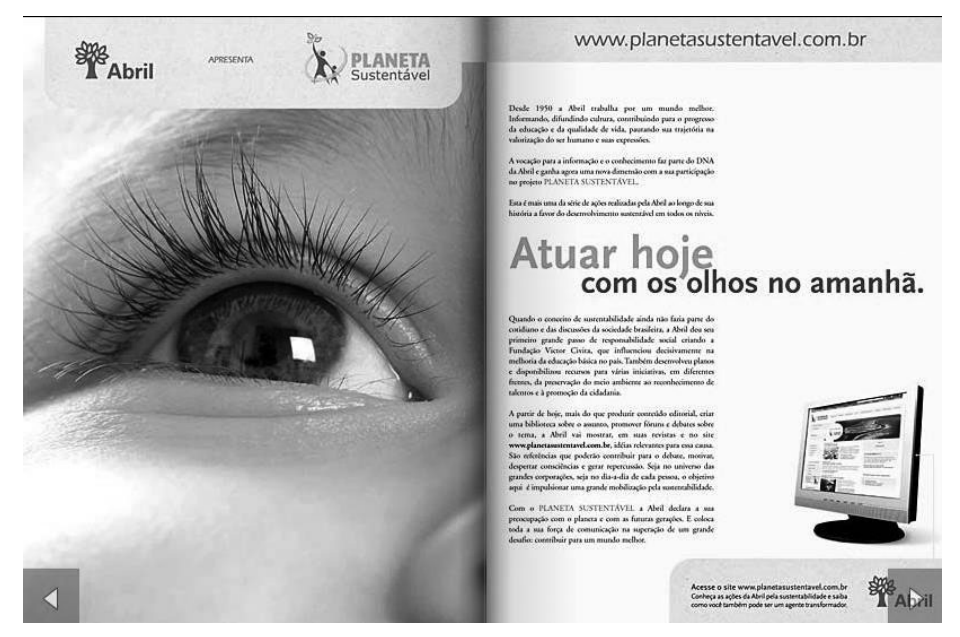

Figura 2 - Revista Veja n²005, de 25/04/2007, p.110-1114

4 Redação do anúncio: Desde 1950 a Abril trabalha por um mundo melhor. Informando, difundindo cultura, contribuindo para o progresso da educação e da qualidade de vida, pautando 
No anúncio (fig. 02), vemos a Abril, uma das maiores editoras do nosso país, mostrando seu compromisso com o meio ambiente e com o futuro das novas gerações. Como observado, o uso da criança na peça serve para sensibilizar e, posteriormente, com a leitura do texto publicitário, podemos perceber a empresa se colocando como uma instituição preocupada com o futuro do planeta - o que é justificado pela escolha de um bebê para protagonizar o anúncio. O que também chama atenção é que, para demonstrar a preocupação com a sustentabilidade do planeta, a imagem de um computador de mesa aparece no canto da página. A inclusão de um aparato tecnológico como o computador indica que, para um planeta se transformar em um lugar sustentável, é necessário que as futuras gerações façam uso das tecnologias digitais. Eis uma das formas encontradas nos anúncios publicitários para mostrar a geração digital.

Outras empresas de telefonia, além da Tim, também apresentam inúmeros anúncios que mostram o quanto as crianças contemporâneas têm sido acionadas para vender os produtos e, consequentemente, acabam por naturalizar a constituição de uma infância digital.

Analisando as peças publicitárias encontramos dois anúncios da empresa Claro. A escolha passa pelo mesmo crivo da anterior e, neste caso, a partir de duas abordagens distintas.

sua trajetória na valorização do ser humano e suas expressões. A vocação para a informação e o conhecimento faz parte do DNA da Abril e ganha agora uma nova dimensão com a sua participação no projeto PLANETA SUSTENTÁVEL. Esta é mais uma da série de ações realizadas pela Abril ao longo de sua história a favor do desenvolvimento sustentável em todos os níveis. Atuar hoje com os olhos no amanhã. Quando o conceito de sustentabilidade não fazia parte do cotidiano e das discussões da sociedade brasileira, a Abril deu seu primeiro grande passo de responsabilidade social criando a fundação Victor Civita, que influenciou decisivamente na melhoria da educação básica no país. Também desenvolveu planos e disponibilizou recursos para várias iniciativas, em diferentes frentes, da preservação do meio ambiente ao reconhecimento de talentos e à promoção da cidadania. A partir de hoje, mais do que produzir conteúdo editorial, criar uma biblioteca sobre o assunto, promover fóruns e debates sobre o tema, a Abril vai mostrar em suas revistas e no site www.planetasustentavel.com.br ideias relevantes para essa causa. São referências que poderão contribuir para o debate, motivar, despertar consciências e gerar repercussão. Seja no universo das grandes corporações, seja no dia-a-dia de cada pessoa, o objetivo aqui é impulsionar uma grande mobilização pela sustentabilidade. Com o PLANETA SUSTENTÁVEL, a Abril declara a sua preocupação com o planeta e com as futuras gerações. E coloco toda a sua força de comunicação na superação de um grande desafio: contribuir para um mundo melhor. Acesse o site www.planetasustentavel.com.br. Conheça as ações da Abril pela sustentabilidade e saiba como você também pode ser um agente transformador. 
No primeiro anúncio (fig.3), veiculado em data próxima ao Dias Das Mães, vemos uma linda menina solicitando que o número de seu telefone seja o primeiro número escolhido por sua mãe para participar da promoção que a empresa está oferecendo. Este anúncio é significativo para mostrar o quanto as crianças estão imersas na cultura digital e o quanto esta inserção é marca do tempo contemporâneo, pois, uma menina tão jovem além de já ter o seu próprio celular, orienta a sua mãe na escolha da empresa de telefonia e dos números que a mesma deve selecionar para participar da promoção. Ou seja, fica evidente que os "nativos" da cultura digital são as crianças e não os adultos.

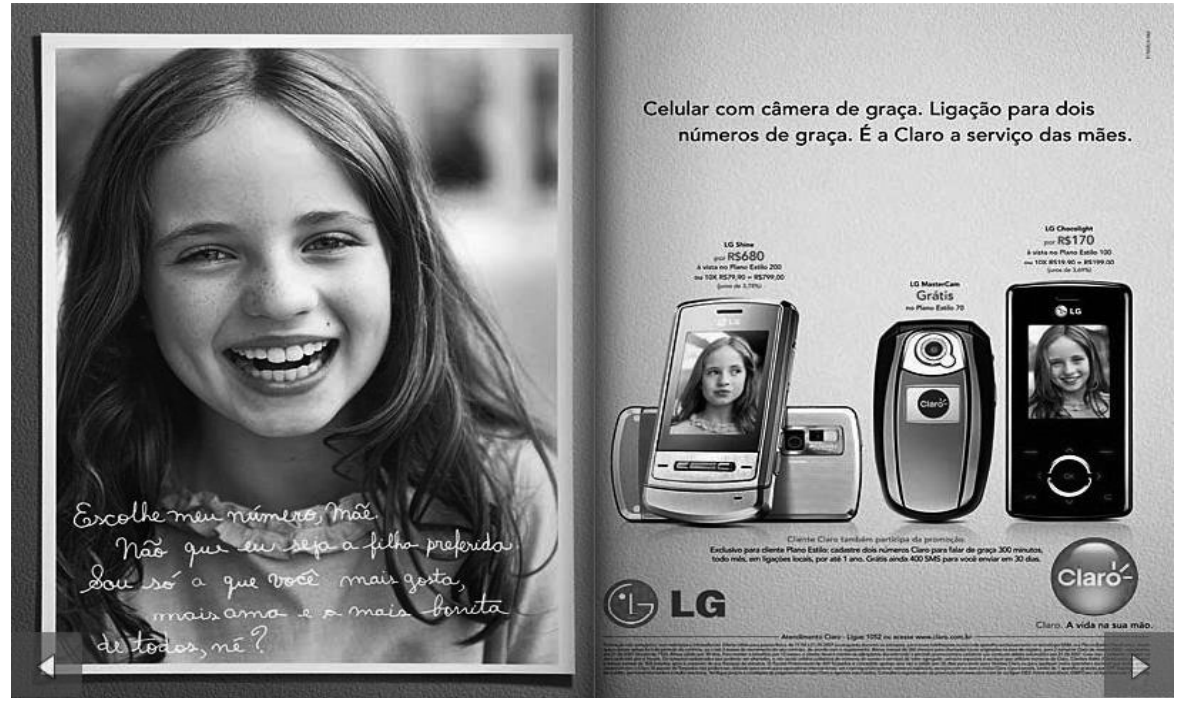

Figura 3 - Revista Veja no 2005, de 25/04/2007, p. 30-315

Em outro anúncio da Claro (fig. 4), a empresa abre mão de anunciar qualquer aparelho celular e concentra-se apenas na exposição de crianças para mostrar o quanto a Claro é uma marca que valoriza a possibilidade de escolhas de seus clientes. O foco na marca, conforme Klein (2004), é uma das principais estratégias contemporâneas para conquistar consumidores. Segundo a autora, "as corporações de sucesso devem produzir principalmente marcas, e não produtos" (p. 27). Para isso, ainda de acordo com Klein (2004), a publicidade sofreu algumas transformações em seu papel nas últimas décadas: passou "do fornecimento de informações sobre os produtos para a construção de uma imagem em torno de uma variedade identificada de produtos" (p. 30).

\footnotetext{
5 Redação do anúncio: Escolhe meu número, mãe. Não que eu seja a filha preferida. Sou só a que você mais gosta, mas e ama e mais bonita de todas, né? Celular com câmera de graça. Ligação para dois números de graça. É a Claro a serviço das mães.
} 
Outro aspecto que também nos chama atenção é o tom erotizado, pois o anúncio se utiliza de um menino e uma menina para mostrar possibilidades de escolha, inclusive em relações afetivas. A empresa não parece ser a pioneira no modo de revelar uma infância precoce, apenas está colocando em circulação uma representação já tida como "normal” pela mídia - assunto de extrema preocupação para pedagogos e pesquisadores do campo da educação, mas que não é foco da análise aqui proposta.

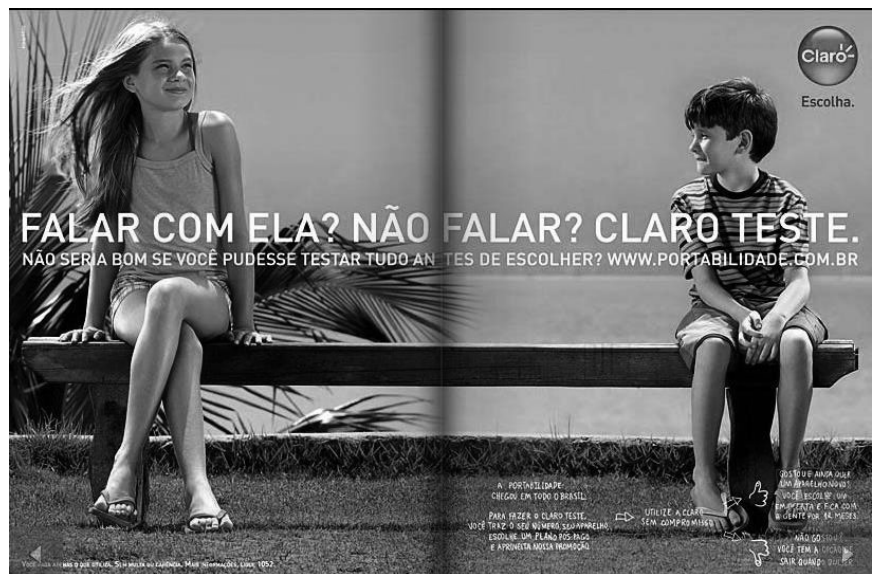

Figura 4 - Revista Veja ${ }^{\circ} 2104$, de 18/03/2009, p. 52-53

A representação da infância aliada aos aparatos digitais vem fortalecendo o argumento de que estes sujeitos são "nativos digitais" e que a publicidade, mesmo colocando em circulação saberes que já estão consolidados no campo social, funciona como uma pedagogia cultural. $\mathrm{O}$ anúncio abaixo, ao relacionar consumo, infância e tecnologia é exemplo disso.

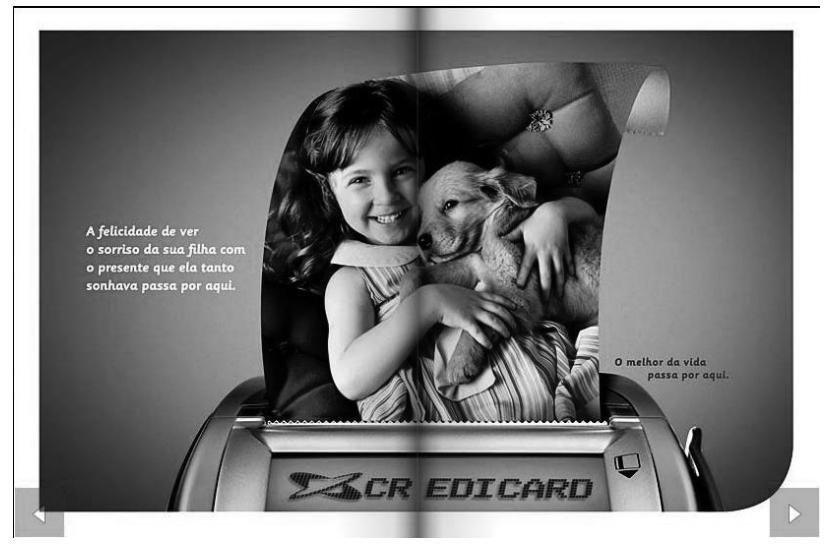

Figura 5 - Revista Veja n 2103, de 11/03/2009, p. 74-75 0

6 Redação do anúncio: A felicidade de ver o sorriso da sua filha com o presente que ela tanto 
Por meio da publicidade da Credicard (fig.5), empresa no ramo dos cartões de crédito, é possível observar o apelo emocional quando alia as condições de consumo com o uso da tecnologia e a felicidade de uma criança. No caso aqui, essa felicidade - impressa na imagem de uma menina agarrada a um filhote de cachorro - acaba por nos revelar aspectos essenciais para olhar tal relação. Uma dessas relações poderia ser pensada no sentido de que o mais importante do que gastar ou mesmo endividar-se, seria a "felicidade da sua filha", fornecendo uma certa justificativa para o consumo. Reforçando tal ideia, a empresa imprime a imagem da criança feliz exatamente como se fosse um comprovante de pagamento efetuado por cartão de crédito.

Com o slogan "o melhor da vida passa por aqui", a peça alia claramente tecnologia e infância, incitando e vendendo a ideia de que ambas são produtos vendáveis e que o poder de compra parece ser uma das "melhores coisas da vida".

Enfim, como podemos perceber a partir das análises, o modo como a infância contemporânea se relaciona com a cultura da atualidade é um dos ensinamentos das pedagogias culturais. Por isso, a infância contemporânea é atravessada tanto pelo consumo quanto pelas tecnologias. Marcas do nosso tempo.

\section{CONSIDERAÇÕES FINAIS}

Quando a tecnologia se apresenta como um aspecto significativo na vida da maioria das crianças e jovens, as relações entre esses mesmos sujeitos e os aparatos tendem a convergir para os meios digitais e, agora, parecem ser indispensáveis às suas vivências. Os sujeitos da Geração Digital absorvem e consomem uma série de artefatos inscritos em aparelhos celulares, computadores, videogames e nos mostram que pertencem ao universo das tecnologias. Eles também nos revelam que estão de acordo com os códigos, tanto materiais como cognitivos, que compõe aquele universo.

Assim, percebe-se que pedagogias precisam ser praticadas para que um sujeito se torne um integrante da Geração Digital. Isso porque é também por intermédio das pedagogias exercidas por estes artefatos, como é o caso da publicidade, que sujeitos se constituem, que suas identidades são compostas, que há uma disseminação de práticas e condutas, enfim, que os delineamento das formas de ser e viver na contemporaneidade são traçados (COSTA, 2010).

sonhava passa por aqui. $\mathrm{O}$ melhor da vida passa por aqui. 
Assim, o conjunto de práticas, atitudes, pensamentos e valores que se desenvolvem junto ao crescimento dos recursos disponíveis - tem engendrado outros modelos de comportamentos e provocado mudanças na construção e nas formas como os sujeitos são produzidos. Portanto, a Geração Digital é uma geração que carrega as marcas do tempo presente, imersos sempre nesta sociedade que Bauman (2008) denominou de sociedade de consumidores.

\section{REFERÊNCIAS}

AMARAL, Marise Basso. Natureza e Representação na pedagogia da publicidade. IN: COSTA, Marisa Vorraber (org.) Estudos Culturais em Educação: mídia, arquitetura, brinquedo, biologia, literatura, cinema... Porto Alegre: Ed. Universidade/UFRGS, 2000. p.143-171

ANDRADE, Paula Deporte de. A formação da infância do consumo - um estudo sobre crianças nos anúncios publicitários da revista Veja. Dissertação (Mestrado em Educação) - Universidade Luterana do Brasil, 2011.

BORTOLAZZO, Sandro Faccin. Vivendo no espetáculo, aprendendo com o espetáculo - a cultura rave e a produção de jovens contemporâneos. Dissertação (Mestrado em Educação) - Universidade Luterana do Brasil, 2010.

BAUMAN, Zygmunt. Vida para consumo. A transformação das pessoas em mercadoria. Trad. Carlos Alberto Medeiros. Rio de Janeiro: Jorge Zahar, 2008.

CAMOZZATO, Viviane. Da Pedagogia Às Pedagogias - formas, ênfases e transformações (Tese de Doutorado) Programa de Pós Graduação em Educação, Faculdade de Educação da Universidade Federal do Rio Grande do Sul.

CASTELLS, Manuel. A sociedade em rede. A era da informação: economia, sociedade e cultura. Volume 1, 3. ed. São Paulo: Paz e Terra, 1999.

COSTA, Marisa Vorraber; SILVEIRA, Rosa M. Hessel.; SOMMER, Luís Henrique. Estudos Culturais, educação e pedagogia. Revista Brasileira de Educação. Campinas, nº 23, p. 36-61, maio/ jun./jul./ago 2003.

COSTA, Marisa Vorraber. Sobre a contribuição das análises culturais para a formação de professores no início do século XXI. Educar em Revista, n 37, agosto-dezembro/2010, Curitiba, PR: Editora UFPR. Dossiê: As dimensões formativas do ensino superior no século XXI: a retomada do sentido democrático na formação inicial e continuada dos profissionais da escola básica.

FEIXA, Carles; LECCARDI, Carmen. O conceito de geração nas teorias sobre a juventude. Sociedade \& Estado, Brasília, Vol.25 n.2, mai - ago 2010.

Grossberg, Lawrence (2009), "Será que os Estudos Culturais têm futuros"? E deverão tê-los? (ou o que se passa com Nova lorque?), In: Revista de Comunicação e Cultura, n. ${ }^{\circ}$ 6: Culturalite, pp. 17-51. 
HALL, Stuart. The work of representation. In: HALL, Stuart (org) Representation: cultural representations and signifying practices. London: Sage Publications, 1997.

KLEIN, Naomi. Sem logo: A tirania das marcas em um planeta vendido. Trad. Ryta Vinagre. $4^{\mathrm{a}}$ ed. Rio de Janeiro: Record, 2004.

LIMA, Lauro de Oliveira. Mutações em educação segundo McLuhan. Petrópolis: Vozes, 1978.

LINN, Susan. Crianças do consumo: a infância roubada. Tradução Cristina Tognelli. São Paulo: Instituto Alana, 2006.

MCLUHAN, Marshall. Os meios de comunicação como extensões do homem. Trad. Décio Pignatari. 18. ed. São Paulo: Cultrix, 2002.

PRENSKY, M. Digital natives, digital immigrants, part I. On the Horizon. Lincoln: NCB University Press, v. 9, $\mathrm{n}^{\circ}$ 5, 2001.

SILVA, Tomaz Tadeu da. Teoria cultural e educação: Um vocabulário Crítico. Belo Horizonte: Autêntica, 2000.

SILVA, Tomaz Tadeu da. O currículo como representação. In: SILVA, Tomaz Tadeu da. 0 currículo como fetiche: a poética e a política do texto curricular. 2. Ed.. Belo Horizonte: Autêntica, 2001.

STEINBERG, Shirley; KINCHELOE, Joe. Sem segredos: cultura infantil, saturação de informação e infância pós-moderna. In: STEINBERG, Shirley; KINCHELOE, Joe (orgs.). Cultura Infantil: a construção corporativa da infância. Trad. George Eduardo Japiassú Brício. - $2^{a}$ Ed. Rio de Janeiro: Civilização Brasileira, 2004. p. 9-52.

TAPSCOTT, Don. Grown up digital: how the net generation is changing your world. New York: McGraw-Hill, 2009.

\section{Revistas Veja analisadas:}

Revista Veja n 2005, de 25/04/2007; Revista Veja n²103, de 11/03/2009; Revista Veja n $^{\circ}$ 2104, de 18/03/2009; Revista Veja n²108, de 15/04/2009.

RECEBIDO EM: 08/10/12

ACEITO PARA PUBLICAÇÃO: 06/11/12 
A GERAÇÃO DIGITAL PRODUZIDA NOS ANÚNCIOS PUBLICITÁRIOS

\section{Paula Deporte de Andrade}

Pedagoga, professora de Anos Iniciais, Mestre em Educação e doutoranda em Educação na linha dos Estudos Culturais

\section{Sandro Faccin Bortolazzo}

Bacharel em Comunicação Social/Jornalismo pela PUCRS, mestre em Educação pela ULBRA na linha de Estudos Culturais e doutorando em Educação pela UFRGS na mesma linha de pesquisa. 